as yet unplaced in biology. They require a name; and having in view their being a branch of the Chytridiales, hence belonging to the vegetable protists with an affinity to the Mycetozoa; and in view of their being in the plasson state at the initial stage of their intracellular life I suggest the name Plassomyxineæ.

References.-1. Cornu, M.: Olpidiopsis Saprolegnice, Annales des Sciences Nat., 1872. 2. Schröter, J. : The Genus Synchytrium, Cohn's Beiträg, i., 1, 1875. 3. Stevens, F. L.: Nuclear Structures in Synchytrium, Annal. Mycolog., v., p. 480, 1907. 4. Curtis, K. M.: Phil. Trans. Roy. Soc. Lond., 1921, pp. 409-478. 5. Lundie, C., and Goss, F. H.: On the Syphilis Organism, The LANCET, Hickson, Ray Lankester's Treatise on Zoology, Part I., Fascicle I.

\section{THE VALUE OF THE}

\section{COMPLEMENT-FIXATION TEST IN PULMONARY TUBERCULOSIS.}

A Report to the Medical Research Council from the Institute of Pathology and Research, St. Mary's Hospital.

By A. LISLE PUNCH, M.B., M.R.C.P.LOND. ASSISTANT PHYSICIAN TO THN BROMPTON HOSPITAL.

\section{Introductory Note by}

Alexander Fleming, F.R.C.S. Eng.

MY connexion with the experiments which Dr. Punch has detailed in this article has been that of a scrutineer and critic. I have had no part in the performance of the experiments, and no part of the credit that may accrue from this investigation belongs to me. When Dr. Punch began to perform these tests in the laboratories of the Institute of Pathology and Research at St. Mary's Hospital his first care was to convince me that the test was sufficiently good to be worth proceeding with; for this purpose he obtained bloods from a number of patients whom he knew to be suffering from pulmonary tuberculosis. These bloods, some 30 in all, were not disguised in any way, but in every case I saw the tubes at the time the reading was taken, and was thus able to check the results. At the same time these tuberculous bloods were tested there was mixed with them a certain number of normal bloods derived from workers in the laboratories or from patients attending for other diseases. In every one of these cases the result of the test corresponded with the clinical condition.

Having thus satisfied me that the investigation was worth while, Dr. Punch proceeded to deal with a more extensive series of cases, and in this series he had no opportunity of knowing the origin of the blood until the results of the test had been recorded. The procedure adopted was as follows:-

The specimens were collected, some by Dr. Punch, others by workers in this or other institutions. The serum was taken from these specimens and inactivated, the tubes were then handed to me, with a list giving the names and clinical diagnosis (including the information as to whether tubercle bacilli were present in the sputum). I then re-numbered the tubes, sometimes splitting a specimen into two or three parts bearing different numbers, and if there was any possibility of any tube being recognised by some irregularity in size, or by its being cracked, I changed the serum from this tube into another of ordinary appearance. The key to these numbers I retained till the tests were completed, and then I myself recorded on the key the results which Dr. Punch dictated to me, after which I compared the results with the clinical diagnosis with which I had been provided.

I am not here going to enter into any discussion as to the results; they are set forth at length by Dr. Punch. All I wish to vouch for is that Dr. Punch had no means of knowing which blood he was dealing with until he had completed the test, and I had recorded the results which he gave me.

\section{Dr. Lisle Punch's Report.}

The work contained in this paper has been carried out in the laboratories of the Institute of Pathology and Research at St. Mary's Hospital by the kind permission of Sir Almroth Wright. In September, 1920, I published in THE LANCET a method for the performance of the complement-fixation test in pulmonary tuberculosis, and the results of a series of cases upon which the test had been performed. This article consists of an analysis of a second series of cases, and offers further proof of the accuracy of the test when performed by this method. 185 bloods have been tested in this series in the manner described above by Dr. Fleming. On an average 12 sera were tested at each experiment.

\section{Analysis of Cases.}

The serum of 185 individuals was examined. Group 1.-C.-F.T. Positive Cases.

71 of the cases gave a positive result.

(A) Cases with tubercle bacilli in the sputum at the time of the performance of the test.. .... (B) Cases in which tubercle bacilli were found in the sputum subsequent to the performance of the test (C) Other cases giving a positive result (these cases are considered in more detail). . .. . . .

Group C.-Case, Initials, and Clinical Condition.

1.-E. J. Crepitations at both apicea; a few weeks Iater a very loud pleural rub over left upper lobe; losing weight
rapidly; sputum negative for T.B. on two occasions.

2.-A. L. Complains of cough and loss of weight; no sputum; crepitations at right apex; husband has phthisis, one brother died of nhthisis.

3-A. M Crepitations both upper lobes; cavitation left upper lobe ; tuberculous laryugitis; sputum only examincd once as yet; negative for T.B.

4 and 5.-A. M. and D. G. Both apparently healthy save for acne ; these and the next case, B.O., are discussed below.

-B. $O$. Gunshot wound of chest.

-D. M. G. Cough, no sputum, loss of weight; no abnormal physical signs in chest; father died of phthisis.

-B. A. Cough, sputum, hæmoptysis pint two years ago ; recent clots: no abnormal physic

-O. C. No symptoms or signs; dry pleurisy seven months ago ; lost a good deal of weight then, subsequently regained it. Treated in sanatorium.

10.-H. A. Considerable hæmoptysis, no other symptome; no abnormal physical signs in chest.

1. - B. Cough, sputum, crepitations left apex, signs of pleural effusion right base; sputum negative for T.B. on

12.-E. P. Sputum positive for T.B. in 1915; some cough and sputum at present : weight stationary; no crepitations now in chest; sputum not yet examined.

13.-A. J. Complains of cough sputum and loss of weight sputum streaked with blood two months ago ; no abnormal physiral signs in chest.

11.-W. H. F. Complains of cough, sputum very slight hæmoptysis; crepitations at right apex.

-T. A. Complains of cough and sputum; pyrexia present crepitations over right lung, especially at base; sputum negative for T. B, on two occasions.

16. - H. P. Cough, no sputum; swinging temperature to $103^{\circ}$ every evening; extensive abnormal physical signs in chest. strength ; crepitations at both apices ; sputum negatire for T.B. on one examination.

18. - V. D. T.B. in the sputum a year ago; cough and sputum at present; no moist sounds at present in chest : sputum negative for ' $\mathrm{T}$. B

19.- - L. K. T.B. in sputum a year ago; no symptoms or abnormal physical signs in chest at present.

CASE 4.-A. M. A patient in apparent health, save for some acne on the face ; test performed on three separate occasions with three different samples of blood; on each occasion a positive result obtained. What exact interpretation should be put on this case is open to argument. In a series of 100 cases of apparently healthy people, or those suffering from diseases other than tuberculosis, this one (or, if Case 6 is included, two) gave a positive result. This patient may pecently have suffered from a small undetected tuberculous lesion, or may be at present suffering from such a lesion, which has not yet given rise to symptoms. In any case it is not surprising that in dealing with so widespread and prevalent a condition as tuberculosis, a positive result should be obtained in a small number (in this series only 1 or 2 per cent.) of apparently healthy people.

CASE 5.-D. G. Also a patient suffering from acne; test performed twice on two different samples of blood; positive result on both occasions. On questioning the patient it was elicited that six months previously she had been treated for enlarged glands in the neck, and on palpation numerous small hard glands could be felt on the right side of the neck. 
CAse 6.-B. O. A gunshot wound of the chest had been received; some evidence of fibrosis of the lung. In this case it would be a difficult matter to say positively that there was no tuberculous infection. All the cases are under observation.

One case gave a negative result; a second test of the same sample of blood gave a positive result. This case was a patient undoubtedly suffering from phthisis with tubercle bacilli in the sputum. The first time the blood was tested the hremolysis in the tube containing antigen and $1 \frac{1}{2}$ M.H.D. of complement was not quite complete (for the significance of these remarks reference should be made to my paper containing a description of the technique of the test), but hæmolysis in the highest dilution of complement appeared well over 50 per cent.; hence a negative result was recorded. On repeating the test with the same sample of serum the hæmolysis in the tube containing $1 \frac{1}{2}$ M.H.D. was again nearly, but not quite, complete, but this time there was nearly complete fixation in the tube containing 1 M.H.D., and a positive result was recorded.

This serum had been split by. Dr. Fleming into three parts, and the tubes re-numbered along with some dozen other bloods. All three parts gave a precisely similar reading. It appears reasonable to presume that the first time the test was performed, by some error in technique an excess of complement had been added to the third tube (i.e., the highest dilution of complement). On reviewing this case it would appear that the result should in the first place have been returned as "doubtful."

\section{Cases Giving a Negative C.-F.T.}

(1) In which there was no suspicion of tuberculosis. Giving the number of the case, initials, and clinlcal condition.
1.-H. A. Cardiac hyper-

2.-P. T. Tabes dorsalis.

3.-P. C. Bronchitis.

5.-W. G.

6.-I. H. Hypertrophied

7.-D. G. Colitis.

8.-T. I. Bronchitis.

9.-R. I. Chronio nephritis.

11.-N. E. Aneurysm

12. - T. V. Auricular fibrilla tion and coarctation of

13. -A. P. Gastric ulcer

14.-A. M. Bronchiectasis.

16.- E. J. Mitral stenosis

17.-W. I. Bronchitis.

18.-A. W. Acne.

19.-D. G. Aortic regurgita-

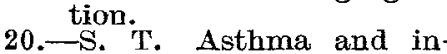

20. S. T. Asthm

21.-C. A. Boils.

22. - S. I. Arre

23.-D. G. Acne.

25.-S. T. Tabes dorsalis.

26. -C. O. Eczema.

27.-I. I. Bronchitic.

28. -K. I. Psoriasis.

29.-W. V. Paralysis agitans.

30. - H. Bronchitis.

31.-Mrs. P. Healthy person.

-R. P. Rhonchi and crepi-

Wans. positive

33.-L. W. Mitral stenosis.

33.-L. W. Mitral sten

35.-F. M. Aortic and mitral

disease. Antestinal stasis.

36.-H. A. Intestinal stasis.

37.-D. V. Rheumatoid

39. - J. S. Bronchitis.

49.-D. S. Bronchitis.

40.-D. E. Rheumatoid

41. T. A. Bronchitis and

42.-F. O. Bronchitis.

45.-R. W. Bronchitis.

47.-F.D. ? Aortic aneurysm

48.- - D. P. Healthy man.

49.-J. O. Auricular fibrilla

50.-C. O. Bronchitis.

51.-Miss M. Healthy med.
6. I. H. Hypertrophied

15.-D. H. Asthma, eczema

tations all over both

38.-M. A. Rheumatoid

42.-F. O. Bronchitis.

44.-D. S. . Bronchitís.
95.-W. S. Adipowity. 13. S. Said to havo had considerablo hemoptysis ary, 1921 ; somo evidonce of bronchitis now. 97.-1I. Acne.
N.A.I'S.
No abuormal physical si

101. C. Mitral stenosis

$102,--J$. G. Ifydatid disease of liver.
98.-C (. Acno.

99. - (1). (t. ,

(2) Cases in which there was a suspicion but no definite evidence of tuberculosis.

1.-W. H. Loss of woight; slight congh; no sputum

2. N.A.B. Angemia ; gencral nalaise ; slight cough ; N.A.P.S.;

sputum negative for 'T.B.
3. C. R. Dry plenrisy three months ago ; signs of thickened pleura; general condition vory good; no symptoms now. sputum negative for $\mathrm{T} \cdot \mathrm{B}$.

5.-A. H. Dry pleurisy January, 1920 ; no symptoms now: 6. N.A.P.S. 7. M. U.

little sin Peurisy seven years ago; slight cough, very 8. -E. B. ? Hæmoptysis; N.A.P.S

9.-W. O. Sputum streaked with blood; no evidence of tuberculosis clinically.

10. -A. D. Sent for examination ; ? phthisis ; no evidence 11. - B. 0 .

Case 22, S. I., undoubtedly had phthisis with T.B. in the sputum a year ago. He now appears perfectly well with no symptoms of abnormal phrsical signs in chest. I sent this case to Dr. Gosse, with no reference to the result of the C.-F.T., asking his opinion. He replied, "I regard this as a case of arrested pulmonary tuberculosis," which was in agreement with the opinion I myself had formed.

One other case remains for special mention. This was a patient, V. F., who came to hospital complaining of cough, in whose chest I could find no abnormal physical signs. The first routine sputum examination was unexpectedly positive for T.B. The C.-F.T. was negative on two separate occasions. It appeared that this was an error in the test, and some slight error of 1 or 2 per cent. is to be expected in any labora. tory test. On endeavouring, however, to confirm the presence of T.B. in the sputum, it was discovered that the patient's cough had cleared up after a week in hospital, and no sputum could be obtained. The possibility, therefore, of an error in the sputum examination cannot be overlooked, and such errors are inevitable. It is certainly very significant that in the only case in which T.B. were said to be present in the sputum which gave a negative result it was impossible to confirm their presence.

\section{A Discrepani Series.}

70. - E. T. Pharyngitis.

70.--E. T. Pharyngitis. tion; Wass pos.

72.-S. T. Aortic risease.

74.-C. C. Pneumonia.

75.-H. K. Bronchitis and

76.-H. A. Acne

76.-H. A. Acne.

fever.

78.-B. A. Bronchitis,

79.-W. F. Aged 14; slight

80. - H. O; Rheumatism.

81. -A. U. Tabes dorsalis ;

82.-B. E. Pos. Rheumatoid

83. B.A. Rheumatoid

84. -K. P. Acne

-W. Einphysema.

6.-A. C. Signs of unilateral fibrosis at lung; sputum 87.

following following pleurisy five 88.- - B. V. Sight skin erup89. -B. A. A Actinomycosis 90.- G. thigh. Slight cough; 91.-W. L. Syphilis: Wass92. - J. P. Cardiac failure. 93.-B. C. Iumbago. 94. W. M. Cardiac degene-
Finally, I should like to draw attention to a series of 50 cases dealt with at the Brompton Hospital in November last. These cases were sent to me by a physician at the Brompton Hospital with numbers only attached to the bloods; the results were returned by me to him, and at a later date I was informed of the clinical diagnosis that had been made. The results of these cases appear to be very contradictory. Of 18 bloods sent to me, and stated to be from patients suffering from phthisis with T.B. in the sputum, 13 were returned as positive and 4 as negative, and 1 , three samples of which it appears were sent, was returned once as positive and twice as negative. Three cases gave a positive result in which it was stated there was clinical evidence of tuberculosis. Seventeen cases gave a negative result, in which there was stated to be no clinical evidence of tuberculosis. Eleven cases were returned as positive, in which there was no clinical evidence of tuberculosis.

These results are very different from my previous published results totalling 202 cases, which, though not done under a similar system of numbering the tubes, were nevertheless uuknown till after the results had been recorded; and tom the present series of 186 , which have been done under comparable conditions, as described by Dr. Fleming: Moreover, I have performed the test at the Brompton Hospital upon some 450 other cases, in which the results were 
comparable to my published rosults, but which $I$ have not had the opportunity to publish.

I am quite unable at present to explain the indifferent results obtained with these cases, but the series which $I$ have detailed in this article has convinced me of the accuracy of my previous published cases, and has also convinced me that the bad results of these 50 cases were dependent upon some fallacy not inherent in the test.

I should like to thank Dr. A. Fleming, Dr. A. H. Gosse, and the medical officers at the St. Marylebone Infirmary for the assistance they have given me in carrying out this work.

\section{Conclusions.}

It would appear that the above results are strictly comparable to those obtained by me previously and published, and that the conclusions drawn from the previous results are confirmed by the present seriesnamely :-

(1) That in the complement-fixation test we have a reliable means for the diagnosis of an active or recently active tuberculous lesion (pulmonary). It inust be emphasised that it is the pulmonary form only of the disease that is dealt with in this paper.

(2) That a negative result is as reliable an indication of the absence of such a lesion as a positive is of its presence.

\section{Climital a dotes:}

\section{MEDICAL, SURGICAL, OBSTETRICAL, AND} THERAPEUTICAL.

TWO PROBABLE CASES OF

\section{A IBULATORY ENCEPHALITI S LETHARGICA.}

By C. Eustace Willials, M.R.C.S. ExG., L.D.S.

THE following cases of what appeared to me to be encephalitis lethargica of the ambulatory type came under my notice during the early part of this year, and are chiefly interesting because the exact dates of onset of the initial symptoms were obtainable in both cases.

CASE 1.-The patient was a woman, aged 23 , recently married. Up to Jan. Sth she felt quite well: on that day, however, she developed a feeling of nausea which lasted for three or four hours. This continued every day until the 21 st, when she was attacked by a fairly severe frontal headache. The next day she consulted me and was given a mixture of tinct. gelsemii $\mathrm{m}$ v., soda bromide gr.v., and water three times a day. On the 25 th the patient began to see double; after three days this suddenly passed off, leaving haziness of vision. On the 29th lethargy made its appearance, the patient feeling an overwhelming desire to sleep alter tea she slept each evening for about four hours, during which time it was possible to wake her up, but she would almost immediately go to sleep again. The medicine was now discontinued, and the symptoms continued until Feb. 9th when the patient was again brought to me. She slept well at night time, was not refreshed on rising, could not remember things as well as formerly, and felt disincline for work.

Examination gave the following details: Pupils equal and regular, pupillary reflexes slow; no ptosis, no Romberg pulse, temperature, and respiration normal; no tremors of hands or tongue; no muscular twitching; cerebration slowed, heart and lungs normal. The patient was given hexamine gr.v., acid socla phosphate gr.x., and water three times a day, and instructed to go to bed. During the following week the temperature never rose above normal. The headache, disordered vision, and lethargy improved on the eighth day patient was allowed to get up, and next day to go out. On the 25th vision again became blurred, and so she was sent to Dr. Fletcher Stiel, ophthalmic surgeon, who reported: "I certainly agree that she is a mild and suppressed case of lethargic encephalitis. ILer actual vision is $6 / 6$ in either eye and her fundi are normal, but her extrinsic muscles are entirely without coördination. I have carefully tested each muselo separately and the result is not that of an ondinary heterophoria at all. There is very definite paresis of third nerve on right side and of the sixth on leit ricle."

Blured vision continned; thres weks later patient complained of a return of intensilied headache and said that her left arm jerked ni night. The hexamine mixture was rropled and a strychnine and iron tonic recommended. 'Thi was continued, and paticnt made a gratual and uninterrupted recovery.

('ASE 2.-The paticnt was a woman, aged 23 , married, with one child. She was suffering from syphilis, and was having her second course of N.A.B. injections when she suddenly ceased attending the V.D. clinic. Shortly after she came to me with the following history : On the morning of Fel. 1st she woke up with a bad frontal headache and a feeling of heaviness behind the eyes. During that day she felt drowsy but did not actually sleep. Next day she complained of "pins and needles" in both arms and legs, and if she concentrated her vision on any object she seemed to go blind. concentrated her vision on any object she seemed to go blind. be roused to talk or take some food before going off to sleep again. These symptoms continued until she came to sce me on the $1 \mathrm{t}$ th, on which date she dereloped a feeling of nausea.

On examination patient presented a dull, heavy appearance, with face pale and practically expressionless; cerebra tion and speech were much slower than usual and she was in a somewhat lethargic condition. Physical examination revealed pupils equal and regular, pupillary reflexes rather sluggish ; no strabismus, no nystagmus, no ptosis; pulse, temperature, and respiration normal, no Romberg, paralysis, or obvious paresis; slight tremors of hands and tongue, no skin eruptions, heart and lungs normal. Patient was given a hexamine mixture and sent to bed. Three days later she was feeling much better, so got up. Symptoms gradually passed off, lethargy being last to go, and by the 21 st she was carrying on her ordinary household duties. She was now given a tonic, and for the next month, with the exception of occasional attacks of giddiness, was her normal self. She then resumed her treatment for syphilis.

The following note was supplied to me by $\mathrm{Dr}$. W. P. White, medical officer to the V.D. clinics of Grimshy and Iincoln, with reference to Case 2 :-

The patient attended my clinic on Oct. 13th, 1920; hes baby was suffering from congenital srphilis; her husband's blood gave a positive Wassermam reaction, and her own also gave a strongly positive reaction. Treatment was at once commenced, intravenous injections of N.A.B. being given once weekly with gr. i. of hydrarg. $\bar{c}$ cret. by mouth t.d.s. The first course consisted of two injections of $0.45 \mathrm{~g}$. N.A.B. and six of $0.6 \mathrm{~g}$. Patient then had a month's rest, after which her blood again gave a positive reaction. The second course of treatment was then commenced; after the first three injections sbe ceased attending; this fact I attributed to ordinary slackness. 'L'he patient had told my clinic nurse that she found it rery difficult to keep awake if sho rested for a few minutes from her house-work. A few davs later the patient's husband informed me that his wife was suffering from sleepy sickness. Later on I saw Dr. Williams, who informed me that he was attending her for encephalitis lethargica." This woukd point to the fact that N.A.B. and its allied arsenical compounds are not a cure for so-called sleepy sickness."

I have seen both patients within a few days of date of writing (June 24 th); both are quite recovered, showing no trace of their recent indispositions.

\section{A FOREIGN BODY IN THE FNEE-JOINT FOR 13 TEARS}

\section{BY AIFred C. Sifarp, M.D. GLaSG.}

Trus patient was a young woman, aged 20 , who visited Harrogate for spa treatment in September, 1920 , on account of pain in the right knee and thigh.

She stated that when she was 7 years of age her right knee was painful and swollen, and a splint was applied for three months. She considered the trouble originated with a knock when 6 years old. She was then all right for seven years, at the end of which period the pain and swelling returned. The knee was thereupon kept in plaster of Paris for six month with no improvement. Later the pain came on at intervals, and although she had sevelal different treatments no improvement occurred. 